\title{
ARTICLE
}

Received 10 Jan 2014 | Accepted 4 Mar 2014 | Published 25 Mar $2014 \quad$ DOl: 10.1038/ncomms4542

\section{Strongly underestimated dispersion energy in cryptophanes and their complexes}

\author{
Gebhard Haberhauer ${ }^{1}$, Sascha Woitschetzki ${ }^{1} \&$ Heinz Bandmann ${ }^{1}$
}

Cryptophanes, composed of two bowl-shaped cyclotriveratrylene subunits linked by three aliphatic linker groups, are prototypal organic host molecules which bind reversibly neutral small guest compounds via London forces. The binding constants for these complexes are usually measured in tetrachloroethane and are in the range of $10^{2}-10^{3} \mathrm{M}^{-1}$. Here we show that tetrachloroethane is-in contrast to the scientific consensus-enclosed by the cryptophane-E cavity. By means of NMR spectroscopy we show that the binding constant for $\mathrm{CHCl}_{3} @$ cryptophane- $\mathrm{E}$ is in larger solvents two orders of magnitudes higher than the one measured before. Ab initio calculations reveal that attractive dispersion energy is responsible for high binding constants and for the formation of imploded cryptophanes which seem to be more stable than cryptophanes with empty cavities.

\footnotetext{
${ }^{1}$ Institut für Organische Chemie, Fakultät für Chemie, Universität Duisburg-Essen, Universitätsstrasse 7, D-45117 Essen, Germany. Correspondence and requests for materials should be addressed to G.H. (email: gebhard.haberhauer@uni-due.de).
} 
$\mathrm{M}$ olecular recognition is required for numerous processes in chemistry and biology. Of high interest are noncovalent host-guest interactions which are mainly dominated by London forces ${ }^{1-6}$. The latter are considered as weak molecular interactions and increase with the size of the interacting moieties. The design of host molecules which efficiently bind small nonpolar guests is a great challenge as dispersion interactions of small guests are less intense owing to their small number of atoms. For binding such guests cage compounds are most suitable as they are able to fully enclose molecules and thereby increase the quantity of dispersion interactions ${ }^{7-9}$. Prominent examples for cage compounds are cryptophanes $^{10-12}$. Cryptophanes are composed of two bowlshaped cyclotriveratrylene (CTV) subunits connected by three aliphatic linker groups, thus forming an interior cavity. Numerous studies have been published which deal with the reversible binding of cryptophane hosts to small nonpolar molecules ${ }^{12}$. Interaction intensities and thus binding constants are highly dependent on the size and shape of the guests and host cavities. By NMR studies it was shown that $D_{3}$-symmetric cryptophane-A $\left(D_{3}-2\right.$, see Fig. 1) forms stable complexes with methane, chloroform and xenon ${ }^{13,14}$. Association constants were determined in 1,1,2,2-tetrachloroethane and amount to $130 \mathrm{M}^{-1}$ for methane and to $230 \mathrm{M}^{-1}$ for chloroform at $298 \mathrm{~K}$ (ref. 13). For xenon an even higher binding constant of $3,000 \mathrm{M}^{-1}$ is found ${ }^{14}$. Here 1,1,2,2-tetrachloroethane was again used as the solvent. It was assumed to be too big to fit into the host cavity, ensuring that the solvent cannot exchange with guest, and that, consequently, the host cavity is empty if no guest is added. If water is used as solvent, the binding constants can be drastically increased. For example, a water-soluble triacetate-functionalized cryptophane-A derivative shows the highest affinity for xenon which was ever measured for a host molecule $\left(K_{\mathrm{i}}=33,000 \mathrm{M}^{-1}\right.$ at $293 \mathrm{~K}$ in buffer $)^{15}$. This increase is explained by entropic (hydrophobic) effects that likely involve desolvation of xenon clathrates upon complexation. An increase of the binding constant can also be observed when the cavity is adjusted to the guest ${ }^{16}$. The $D_{3}$-symmetric cryptophane-E ( $D_{3}-1$, see Fig. 1) has a slightly larger cavity than cryptophane-A and therefore binds chloroform with a higher association constant $\left(K_{\mathrm{i}}=470 \mathrm{M}^{-1} \text { at } 300 \mathrm{~K} \text { in } \mathrm{C}_{2} \mathrm{D}_{2} \mathrm{Cl}_{4}\right)^{17,18}$.

Recently, we were able to show that modified marine cyclopeptides, which are structurally similar to CTVs, can be synthesized in a few steps ${ }^{19-21}$. Structural investigations of modified marine cyclopeptides revealed that small-halogenated hydrocarbons, such as methylene chloride or chloroform, are enclosed into the solid ${ }^{22-24}$. One of these azole-containing cyclopeptides is the $C_{3}$-symmetric cavitand 3 (Fig. 1) which forms a very strong complex with chloroform and other trihalomethanes ${ }^{25}$. As the equilibrium is so strongly shifted to the side of the complex, the thermodynamic parameters of the complex $\mathrm{CHCl}_{3} @ 3$ were determined by temperature-dependent NMR spectroscopy at temperatures between 353 and $398 \mathrm{~K}$ in $1,1,2,2-\mathrm{C}_{2} \mathrm{D}_{2} \mathrm{Cl}_{4}$. From the enthalpy $\left(\Delta H_{\mathrm{i}}\right)$ and entropy $\left(\Delta S_{\mathrm{i}}\right)$ of inclusion determined at these temperatures it was possible to calculate the free enthalpy of inclusion $\left(\Delta G_{\mathrm{i}}\right)$ and hence the binding constant at $300 \mathrm{~K}$. At this temperature $K_{\mathrm{i}}$ amounts to $140,000 \mathrm{M}^{-1}$ for $\mathrm{CHCl}_{3} @ 3$ and is thus two orders of magnitude higher than the binding constants for $\mathrm{CHCl}_{3} @ 1$ and $\mathrm{CHCl}_{3} @ 2$, respectively. One explanation for this huge difference is probably the fact that chloroform perfectly fits to the shape of the trigonal bipyramidal cavity of $\mathbf{3}$, resulting in a multitude of dispersion interactions between the chloroform molecule and the atoms of the cavity. Furthermore, we speculated that a further possible reason for the high stability of $\mathrm{CHCl}_{3} @ 3$ compared with that of $\mathrm{CHCl}_{3} @ 1$ and $\mathrm{CHCl}_{3} @ 2$ may be that the cryptophanes do not completely exclude the solvent, while the container 3 shows improved size discrimination ${ }^{25}$.

Here we describe the reinvestigation of cryptophane-guest complexes and focus on the question to which extent $\mathrm{C}_{2} \mathrm{H}_{2} \mathrm{Cl}_{4}$ is enclosed by the cavity. As a representative example we chose the $\mathrm{CHCl}_{3} @$ cryptophane-E complex $\left(\mathrm{CHCl}_{3} @ 1\right)$. By quantum chemical calculations and NMR spectroscopy we show that the solvent is also bound within the cavity and that the binding constant for $\mathrm{CHCl}_{3} @ 1$ is two orders of magnitude higher than measured before. Cryptophanes with empty cavities are just reactive intermediates which turn over to more stable forms, the so-called imploded cryptophanes.

\section{Results}

Determination of the binding constants. The assumption that-in contrast to the scientific consensus $-\mathrm{C}_{2} \mathrm{H}_{2} \mathrm{Cl}_{4}$ is also enclosed by cryptophanes can be proven by binding constant determination of cryptophane-E $\left(D_{3}-1\right)$ with chloroform in different solvents. If the solvents are enclosed as well, lower binding constants of chloroform should be obtained in these solvents. Crystals containing cryptophane-E and chloroform in a ratio of $1: 2$ were measured in different deuterated solvents $\left(\mathrm{C}_{2} \mathrm{D}_{2} \mathrm{Cl}_{4}\right.$, $\mathrm{C}_{6} \mathrm{D}_{5} \mathrm{Cl}, \mathrm{C}_{6} \mathrm{D}_{5} \mathrm{Br}$ and $1,2-\mathrm{C}_{6} \mathrm{D}_{4} \mathrm{Cl}_{2}$ ) at varying concentrations (Fig. 2, Table 1 and Supplementary Figs 1-3). In decalin, which is even larger, $\mathrm{CHCl}_{3} @$ cryptophane-E was not soluble.

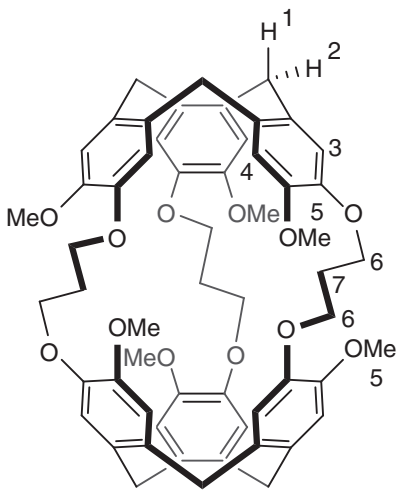

$D_{3}-1$ (cryptophane-E)

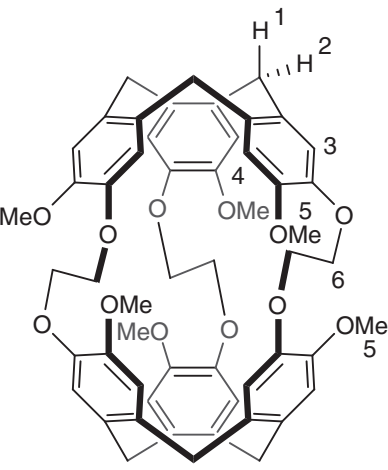

$D_{3}-2$ (cryptophane-A)
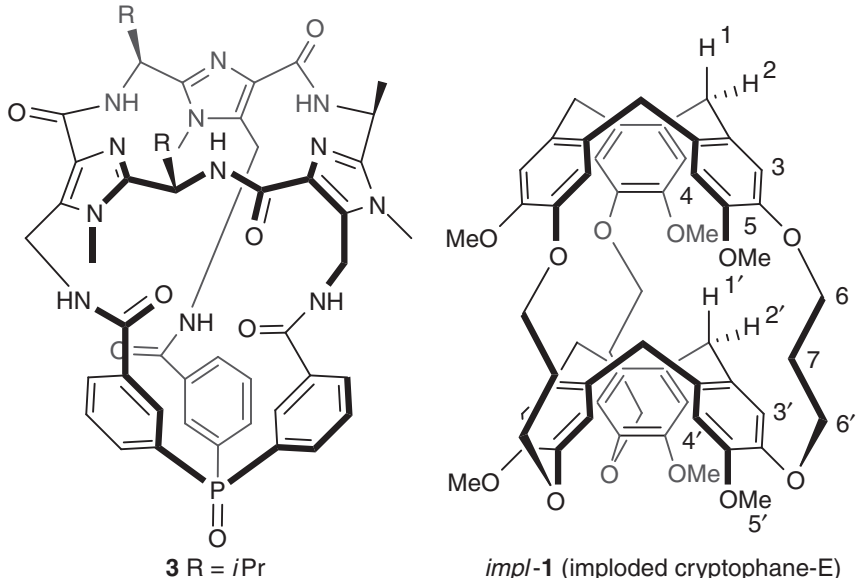

impl-1 (imploded cryptophane-E)

Figure 1 | Host molecules. Structures of cryptophane-E $\left(D_{3}-\mathbf{1}\right)$, cryptophane- $A\left(D_{3}-\mathbf{2}\right)$, the imidazole-containing container $\mathbf{3}$ and imploded cryptophane-E (impl-1). 
The inclusion of chloroform is strongly dependent on the solvent; in $\mathrm{C}_{2} \mathrm{D}_{2} \mathrm{Cl}_{4}, \mathrm{C}_{6} \mathrm{D}_{5} \mathrm{Cl}$ and $\mathrm{C}_{6} \mathrm{D}_{5} \mathrm{Br}$ a $\mathrm{CHCl}_{3} @$ cryptophane$\mathrm{E} /$ cryptophane-E ratio from $1: 1$ to $8: 1$ is found at millimolar host and guest concentrations. The corresponding binding constants amount from 250 to $940 \mathrm{M}^{-1}$. As already reported ${ }^{26}$ the value in $\mathrm{C}_{2} \mathrm{D}_{2} \mathrm{Cl}_{4}$ is significantly lower than the one published by Collet and collegues ${ }^{18}$. This can probably be ascribed to the inaccuracy of determining the chloroform-free cryptophane-E concentration. The error presumably amounts to $\pm 20 \%$.

In 1,2-dichlorobenzene at millimolar host and guest concentrations the $\mathrm{CHCl}_{3} @$ cryptophane-E complex exists exclusively. Further dilution to $10^{-4}$ and $10^{-5} \mathrm{M}^{-1}$ leads to NMR signal sets (800 scans) of cryptophane-E without enclosed chloroform (Fig. 2; Supplementary Fig. 3). The complex formation constant in 1,2-dichlorobenzene amounts to $26,000 \mathrm{M}^{-1}$. The impressive difference in the complex formation constants depending on the solvent used shows that the solvent has to be a part of the equilibrium. One possible interpretation is-as already assumed $^{25}$-that the solvent can also be enclosed by cryptophane-E. Larger solvent molecules like $1,2-\mathrm{C}_{6} \mathrm{D}_{4} \mathrm{Cl}_{2}$ are less effectively enclosed and therefore lead to higher chloroform binding constants, whereas solvents like $\mathrm{C}_{2} \mathrm{D}_{2} \mathrm{Cl}_{4}$ show lower $\mathrm{CHCl}_{3} @ 1$ binding constants. Thus, measurements in such solvents significantly underestimate the binding capability of cryptophanes.

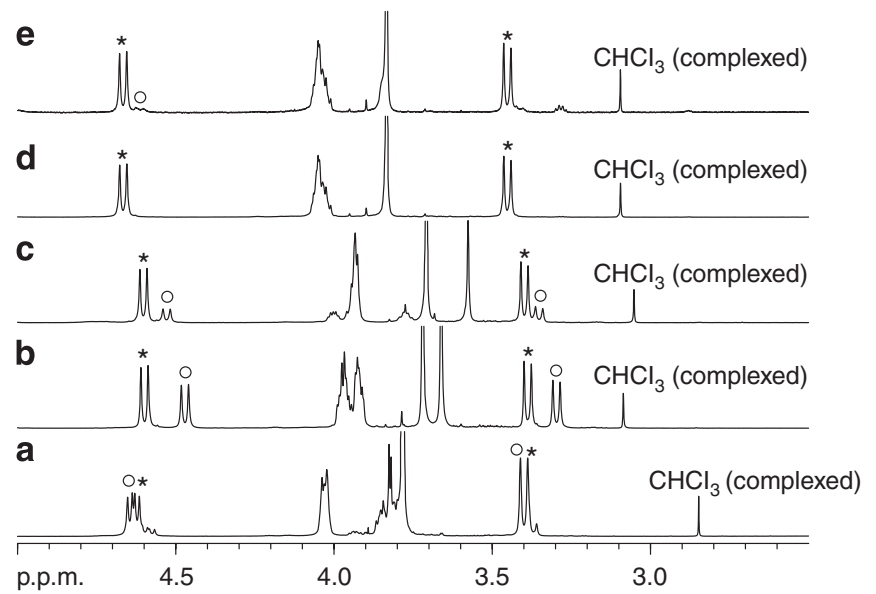

Figure 2 | Cryptophane-E and $\mathrm{CHCl}_{3} @$ cryptophane-E in different solvents. Part of the ${ }^{1} \mathrm{H}$ NMR spectra of cryptophane-E (1) without included chloroform and $\mathrm{CHCl}_{3} @$ cryptophane- $\mathrm{E}$ at $600 \mathrm{MHz}$ in $\mathrm{C}_{2} \mathrm{D}_{2} \mathrm{Cl}_{4}$ (a), $\mathrm{C}_{6} \mathrm{D}_{5} \mathrm{Cl}$ (b), $\mathrm{C}_{6} \mathrm{D}_{5} \mathrm{Br}$ (c), and $\mathrm{C}_{6} \mathrm{D}_{4} \mathrm{Cl}_{2}$ (d and e) at $298 \mathrm{~K}$. The sum of the concentrations of $\mathbf{1}$ without included chloroform and $\mathrm{CHCl}_{3} @ \mathbf{1}$ amounts to $1.79 \mathrm{mM}^{-1}$ (a), $1.46 \mathrm{mM}^{-1}$ (b), $2.46 \mathrm{mM}^{-1}$ (c), $0.835 \mathrm{mM}^{-1}$ (d) and $0.104 \mathrm{mM}^{-1}$ (e). Stars denote protons $\mathrm{H} 1$ and $\mathrm{H} 2$ of $\mathrm{CHCl}_{3} @ \mathbf{1}$, and circles stand for the signals of protons $\mathrm{H} 1$ and $\mathrm{H} 2$ of $\mathbf{1}$ without included chloroform (for numbering see Fig. 1).
Imploded cryptophane-E. Following the above argument the NMR signals for cryptophane-E without chloroform should not be derived from empty cryptophane-E, but from solvent@cryptophane-E. We thus had to find out if the empty cryptophane can also be observed by NMR measurements because this would be a proof for the solvent@cryptophane-E complexes. For this purpose the NMR samples were heated stepwise to $378 \mathrm{~K}$, as higher temperatures should favour the exclusion of chloroform and the solvent, so that an empty container is generated owing to entropy gain. However, increased temperatures lead to faster molecule exchange and thus just one set of NMR signals for cryptophane-E and its chloroform complex are observed at temperatures higher than $338 \mathrm{~K}$ (Fig. 3; Supplementary Figs 4 and 5). But at $338 \mathrm{~K}$ and above there is one additional set of signals pointing to a $C_{3}$-symmetric-imploded cryptophane-E (impl-1; see Fig. 1). After cooling to $298 \mathrm{~K}$ both signal sets (for cryptophane-E with and without chloroform) reoccur and the additional set of signals for the imploded cryptophane-E is also visible. At $298 \mathrm{~K}$ the transformation of impl-1 to the solvent@1 complex takes place very slowly (several days).

The occurrence of one $C_{3}$-symmetric set of signals for impl-1 can either mean that impl-1 adopts a $C_{3}$-symmetric in-out conformation or that it exhibits a $C_{1}$-symmetric out-saddle conformation $^{12}$ which leads to a $C_{3}$-symmetric spectrum owing to pseudorotation ${ }^{27}$. The latter conformation has already been described for cryptophane-A derivatives and larger cryptophanes $^{16,28,29}$. To determine the conformation of impl-1, a mixture of $\mathrm{CHCl}_{3} @ 1$ in $1,2-\mathrm{C}_{6} \mathrm{D}_{4} \mathrm{Cl}_{2}$ was heated at $423 \mathrm{~K}$ for $12 \mathrm{~h}$ to completely remove $\mathrm{CHCl}_{3}$ from the solution. In a second experiment $\mathrm{CHCl}_{3} @ 1$ in $\mathrm{C}_{6} \mathrm{D}_{5} \mathrm{Cl}$ was heated at $393 \mathrm{~K}$ for $12 \mathrm{~h}$. Both experiments resulted in a 2:1 mixture of impl-1 and solvent@1 which was analysed by variable temperature and two-dimensional nuclear Overhauser enhancement spectroscopy (NOESY) experiments. The NOESY spectra show no distinct cross peaks between the protons of opposite CTV units. In the temperature-dependent NMR spectra the signal for proton $\mathrm{H}^{\prime}{ }^{\prime}$ becomes broader owing to decreasing temperature (Supplementary Figs 6 and 7). Both results suggest a dynamic process which unambiguously points to the $C_{1}$-symmetric out-saddle conformation of impl-1.

Proof of the inclusion of $\mathrm{C}_{2} \mathrm{H}_{2} \mathrm{Cl}_{4}$ into cryptophane-E. To deliver a direct proof that $1,1,2,2-\mathrm{C}_{2} \mathrm{H}_{2} \mathrm{Cl}_{4}$ is enclosed by cryptophane-E we decided to analyse a mixture of $\mathrm{C}_{2} \mathrm{H}_{2} \mathrm{Cl}_{4} @ 1$ and $\mathrm{CHCl}_{3} @ 1$ in $\mathrm{C}_{2} \mathrm{H}_{2} \mathrm{Cl}_{4}$ with ca. 9\% of $\mathrm{C}_{2} \mathrm{D}_{2} \mathrm{Cl}_{4}$. The occurrence of a highfield-shifted signal for the protons of $\mathrm{C}_{2} \mathrm{H}_{2} \mathrm{Cl}_{4}$ in $\mathrm{C}_{2} \mathrm{H}_{2} \mathrm{Cl}_{4} @ 1$ should be a proof for the formation of $\mathrm{C}_{2} \mathrm{H}_{2} \mathrm{Cl}_{4} @ 1$. The strong solvent signal of $\mathrm{C}_{2} \mathrm{H}_{2} \mathrm{Cl}_{4}$ in the ${ }^{1} \mathrm{H}$ NMR spectrum made it necessary to use higher concentrations of $\mathrm{CHCl}_{3} @ \mathbf{1}$. However, this higher concentration leads to the existence of only $\mathrm{CHCl}_{3} @ 1$ (Supplementary Fig. 8). To completely remove the

\begin{tabular}{|c|c|c|c|c|c|}
\hline Host & Solvent & $\Delta \delta$ & $T(K)$ & $K_{\mathrm{i}}\left(\mathrm{M}^{-1}\right)$ & $\Delta G_{i}$ \\
\hline \multirow[t]{4}{*}{$D_{3}-1$} & $\mathrm{C}_{2} \mathrm{D}_{2} \mathrm{Cl}_{4}$ & 4.44 & 300 & 470 (ref. 18) & -3.7 \\
\hline & $\mathrm{C}_{6} \mathrm{D}_{5} \mathrm{Cl}$ & 3.64 & 298 & $870 \pm 50$ & -4.0 \\
\hline & $\mathrm{C}_{6} \mathrm{D}_{5} \mathrm{Br}$ & 3.72 & 298 & $940 \pm 50$ & -4.1 \\
\hline & $\mathrm{C}_{6} \mathrm{D}_{4} \mathrm{Cl}_{2}$ & 4.02 & 298 & $26,000 \pm 4,000$ & -6.0 \\
\hline
\end{tabular}


chloroform the solution was heated at $413 \mathrm{~K}$ for $20 \mathrm{~h}$. In the resulting solution, exclusively the signals for $\mathrm{C}_{2} \mathrm{H}_{2} \mathrm{Cl}_{4} @ \mathbf{1}$ and impl-1 are found. The signal for enclosed $\mathrm{C}_{2} \mathrm{H}_{2} \mathrm{Cl}_{4}$ can be found at 1.58 p.p.m. (Supplementary Fig. 9). An unambiguous proof that this signal indeed belongs to the enclosed solvent can be found in the NOESY spectrum, which exhibits a cross peak between free $\mathrm{C}_{2} \mathrm{H}_{2} \mathrm{Cl}_{4}$ at 5.99 p.p.m. and enclosed $\mathrm{C}_{2} \mathrm{H}_{2} \mathrm{Cl}_{4}$ at 1.58 p.p.m. (Fig. 4). To verify that this signal is no artefact caused by the high concentration of nondeuterated solvent, the NOESY spectrum was monitored using a different spectrometer frequency $(600 \mathrm{MHz})$. At this frequency the exchange signal can also be observed.

Further investigations were made to prove the exchange signal utilising rotating-frame Overhauser effect spectroscopy (ROESY) and selective ROESY techniques, which are ideally suited for identifying chemical exchange processes ${ }^{30}$. The sign of the cross peak immediately discriminates between cross relaxation chemical exchange types of magnetisation transfer. As expected a negative sign is found for the cross signal of the protons at 5.99 and 1.58 p.p.m., whereas NOE cross peaks (for example, the cross

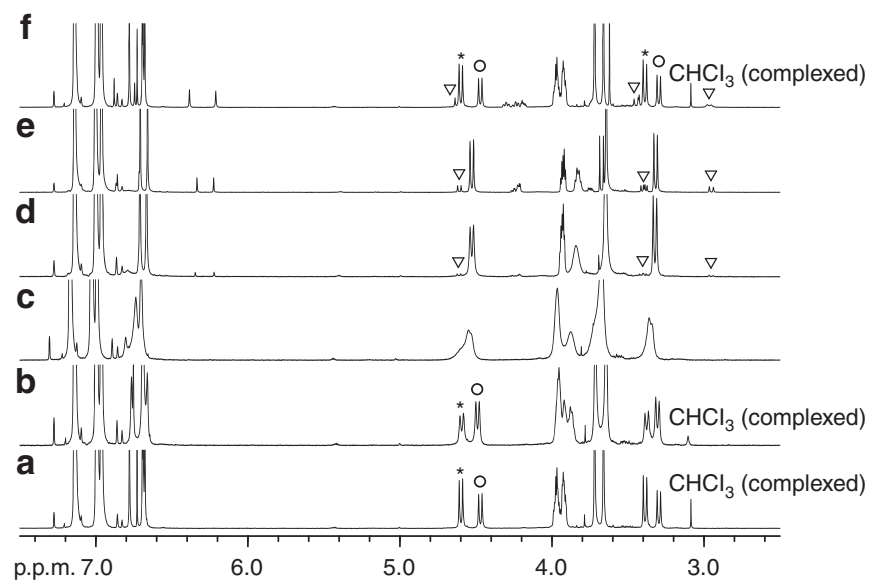

Figure 3 | Cryptophane-E and $\mathrm{CHCl}_{3} @$ cryptophane-E in $\mathrm{C}_{6} \mathrm{D}_{5} \mathbf{C l}$ at different temperatures. ${ }^{1} \mathrm{H}$ NMR spectra of cryptophane- $\mathrm{E}\left(D_{3}-\mathbf{1}\right)$ without included chloroform and $\mathrm{CHCl}_{3} @$ cryptophane- $\mathrm{E}$ at $600 \mathrm{MHz}$ in $\mathrm{C}_{6} \mathrm{D}_{5} \mathrm{Cl}$ at $298 \mathrm{~K}(\mathbf{a}), 318 \mathrm{~K}(\mathbf{b}), 338 \mathrm{~K}(\mathbf{c}), 358 \mathrm{~K}(\mathbf{d}), 378 \mathrm{~K}(\mathbf{e})$ and after cooling to $298 \mathrm{~K}$ (f). Stars denote protons $\mathrm{H} 1$ and $\mathrm{H} 2$ of $\mathrm{CHCl}_{3} @ \mathbf{1}$, circles stand for the signals of protons $\mathrm{H} 1$ and $\mathrm{H} 2$ of $D_{3}-1$ without included chloroform, and triangles mark protons $\mathrm{H} 1, \mathrm{H}^{\prime}, \mathrm{H} 2$ and $\mathrm{H}^{\prime}$ of the imploded cryptophane-E (impl-1) (for numbering see Fig. 1). peaks of protons $\mathrm{H} 1$ and $\mathrm{H} 2$; see Supplementary Figs 10 and 11) exhibit positive signs. Further evidence for the inclusion of $\mathrm{C}_{2} \mathrm{H}_{2} \mathrm{Cl}_{4}$ is delivered by the ${ }^{1} \mathrm{H}-{ }^{13} \mathrm{C}$ correlation spectroscopy NMR spectrum, in which a cross peak between the hydrogen of the complexed $\mathrm{C}_{2} \mathrm{H}_{2} \mathrm{Cl}_{4}$ and the carbon of the complexed $\mathrm{C}_{2} \mathrm{H}_{2} \mathrm{Cl}_{4}$ appears (Supplementary Fig. 12).

Calculation of the cryptophanes and their complexes. To evaluate the contribution of attractive dispersion forces to the energy of the inclusion, $a b$ initio calculations were carried out. The molecular structures of the cryptophanes and their complexes were optimized using the density functional theory (DFT) potential M05-2X which has been shown to cover midrange correlation $^{31}$. For the light elements $\mathrm{C}, \mathrm{H}$ and $\mathrm{O}$ the $6-31 \mathrm{G}^{*}$ basis set was used, whereas for the halogens $\mathrm{Cl}$ and $\mathrm{Br}$ the cc-pVTZ basis set was employed. The calculation results are summarized together with the ones obtained for the imidazole-containing container 3 in Table 2 (Fig. 5, Supplementary Fig. 13, Supplementary Table 1 and Supplementary Data 1). A comparison of the calculated (M05-2X) interaction energies of different cryptophane-E complexes shows that in accordance with the experiments the inclusion of all chosen solvent molecules

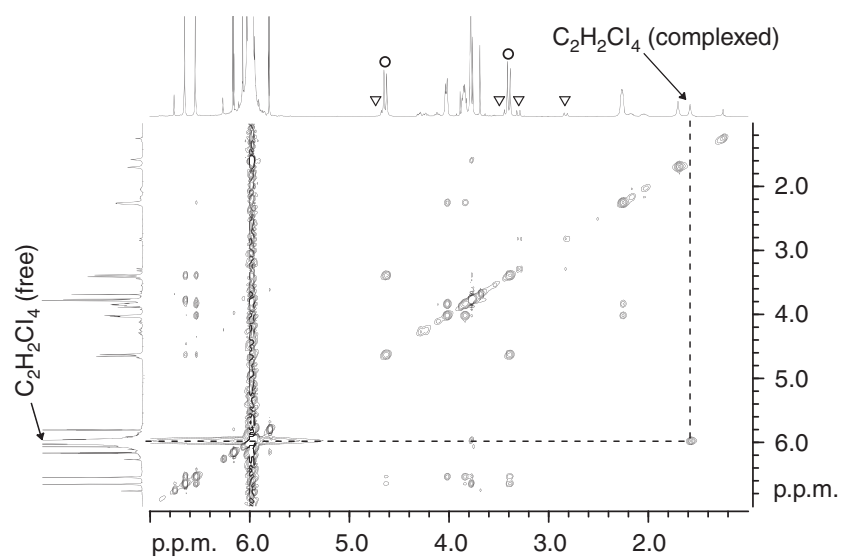

Figure 4 | NOESY NMR spectrum of $\mathrm{C}_{2} \mathrm{H}_{2} \mathrm{Cl}_{4} @ 1$ and imploded cryptophane-E. ${ }^{1} \mathrm{H}-{ }^{1} \mathrm{H}$ NOESY NMR spectrum of $\mathrm{C}_{2} \mathrm{H}_{2} \mathrm{Cl}_{4} @ \mathbf{1}$ and impl-1 at $500 \mathrm{MHz}$ in $\mathrm{C}_{2} \mathrm{H}_{2} \mathrm{Cl}_{4} / \mathrm{C}_{2} \mathrm{D}_{2} \mathrm{Cl}_{4}$ (10:1) at $298 \mathrm{~K}$. The cross peak between the complexed $\mathrm{C}_{2} \mathrm{H}_{2} \mathrm{Cl}_{4}$ and the free $\mathrm{C}_{2} \mathrm{H}_{2} \mathrm{Cl}_{4}$ is highlighted. Circles denote protons $\mathrm{H} 1$ and $\mathrm{H} 2$ of $\mathrm{C}_{2} \mathrm{H}_{2} \mathrm{Cl}_{4} @ \mathbf{1}$, and triangles stand for protons $\mathrm{H} 1, \mathrm{H}^{\prime}, \mathrm{H} 2$ and $\mathrm{H}_{2}^{\prime}$ of impl-1 (for numbering see Fig. 1).

Table 2 | Calculated interaction energies.

\begin{tabular}{|c|c|c|c|c|}
\hline Host & Guest & $\Delta E_{\mathrm{i}}(\mathrm{M} 05-2 \mathrm{X})^{\star}$ & $\Delta E_{\mathrm{i}}(\mathrm{B} 3 L Y P)^{\dagger}$ & $\Delta E_{\mathrm{i}}(\mathrm{B} 3 \mathrm{LYP}-\mathrm{D} 3)^{\ddagger}$ \\
\hline \multirow{6}{*}{$D_{3}-1$} & $\mathrm{CHCl}_{3}$ & -16.4 & +6.6 & -24.4 \\
\hline & $\mathrm{CH}_{2} \mathrm{Cl}_{2}$ & -14.8 & +3.5 & -21.2 \\
\hline & $1,1,2,2-\mathrm{C}_{2} \mathrm{H}_{2} \mathrm{Cl}_{4}$ & -15.0 & +18.7 & -25.2 \\
\hline & $\mathrm{C}_{6} \mathrm{H}_{5} \mathrm{Cl}$ & -12.8 & +16.8 & -24.0 \\
\hline & $\mathrm{C}_{6} \mathrm{H}_{5} \mathrm{Br}$ & -10.9 & +17.9 & -23.2 \\
\hline & $1,2-\mathrm{C}_{6} \mathrm{H}_{4} \mathrm{Cl}_{2}$ & -10.8 & +22.0 & -24.0 \\
\hline \multirow[t]{2}{*}{$D_{3}-2$} & $\mathrm{CHCl}_{3}$ & -17.8 & +7.5 & -25.6 \\
\hline & $1,1,2,2-\mathrm{C}_{2} \mathrm{H}_{2} \mathrm{Cl}_{4}$ & -8.9 & +25.9 & -18.4 \\
\hline \multirow[t]{2}{*}{3} & $\mathrm{CHCl}_{3}$ & -20.5 & +7.3 & -26.5 \\
\hline & $1,1,2,2-\mathrm{C}_{2} \mathrm{H}_{2} \mathrm{Cl}_{4}$ & +9.2 & +47.8 & +2.2 \\
\hline \multicolumn{5}{|c|}{ 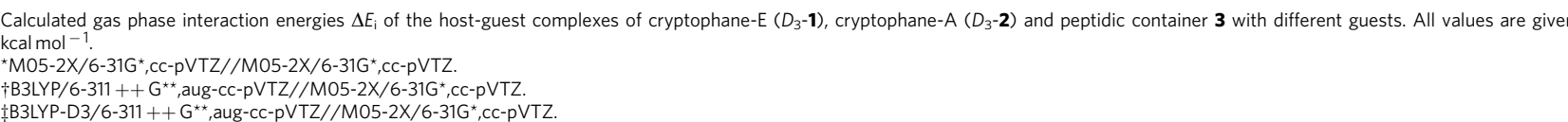 } \\
\hline
\end{tabular}


is possible. The difference of gas phase complex formation energies between $\mathrm{CHCl}_{3} @ \mathbf{1}$ and $\mathrm{C}_{2} \mathrm{H}_{2} \mathrm{Cl}_{4} @ \mathbf{1}$ is just marginal $\left(1.4 \mathrm{kcal} \mathrm{mol}^{-1}\right)$. The experimentally determined preference of $\mathrm{CHCl}_{3} @ 1$ complex formation in $\mathrm{C}_{2} \mathrm{H}_{2} \mathrm{Cl}_{4}$ has thus to be ascribed for entropic reasons. Even for the smaller cryptophane-A the inclusion of $\mathrm{C}_{2} \mathrm{H}_{2} \mathrm{Cl}_{4}$ is energetically possible. Only for imidazolecontaining container 3 the inclusion of $\mathrm{C}_{2} \mathrm{H}_{2} \mathrm{Cl}_{4}$ leads to an energetic destabilization of the system.

Figure 5 depicts the calculated (M05-2X) structures of cryptophane-E $\left(D_{3}-1\right)$ with different guests. It is evident that despite different guests the cryptophane-E host structures of all complexes do not vary significantly. The distances between the middle $\mathrm{CH}_{2}$-propane groups in the complexes amount to $10.33 \AA$ on average $\left(10.27 \AA\right.$ for $\mathrm{CHCl}_{3} @ 1,10.35 \AA$ for $\mathrm{C}_{2} \mathrm{H}_{2} \mathrm{Cl}_{4} @ \mathbf{1}$ and $10.38 \AA$ for $\left.\mathrm{C}_{6} \mathrm{H}_{4} \mathrm{Cl}_{2} @ 1\right)$ and the distances between the methylene groups of opposite CTV units are $9.91 \AA$ on average $(9.91 \AA$ for $\mathrm{CHCl}_{3} @ 1,9.92 \AA$ for $\mathrm{C}_{2} \mathrm{H}_{2} \mathrm{Cl}_{4} @ 1$ and $9.91 \AA$ for $\left.\mathrm{C}_{6} \mathrm{H}_{4} \mathrm{Cl}_{2} @ \mathbf{1}\right)$. The guests are oriented in such a way that the large atoms (chlorine) preferably lie within the plane formed by the middle $\mathrm{CH}_{2}$-propane groups.

Based on the geometries obtained by M05-2X/6-31G*, cc-pVTZ, single point calculations with B3LYP $32-34$ and B3LYP-D3 were carried out. While the first method cannot describe the dispersion interaction correctly, especially not at large distances, the latter one includes an additional dispersion correction $^{35,36}$. Thus, the difference between the two is a hint to the extent of the complex dispersion energies. For the light
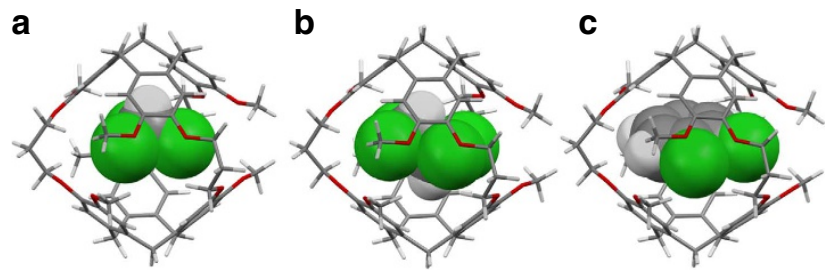

Figure 5 | Molecular structures of inclusion complexes of cryptophane-E. The geometry of the complexes $\mathrm{CHCl}_{3} @ \mathbf{1}(\mathbf{a}), \mathrm{C}_{2} \mathrm{H}_{2} \mathrm{Cl}_{4} @ \mathbf{1}$ (b) and $\mathrm{C}_{6} \mathrm{H}_{4} \mathrm{Cl}_{2} @ 1$ (c) was optimized using M05-2X/6-31G ${ }^{\star}, \mathrm{cc}-\mathrm{pVTZ}$.

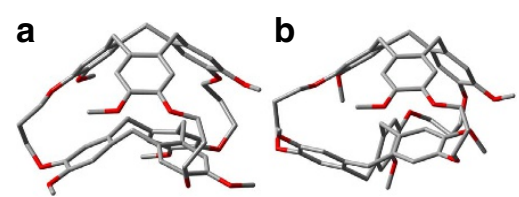

Figure 6 | Structure of imploded cryptophane-E. Molecular structures of imploded cryptophane-E (impl-1) ((a) in-out conformation; (b) saddle-out conformation) calculated using M05-2X/6-31G ${ }^{\star}, \mathrm{cc}-\mathrm{pVTZ}$. All hydrogen atoms are omitted for clarity. elements $\mathrm{C}, \mathrm{H}$ and $\mathrm{O}$ the $6-311++\mathrm{G}^{\star \star}$ basis set was used, whereas for the halogens $\mathrm{Cl}$ and $\mathrm{Br}$ the aug-cc-pVTZ basis set was employed. The data thus obtained are summarized in Table 2. A comparison of the methods B3LYP and B3LYP-D3 shows that in all cases dispersion interactions are predicted to be the driving force for inclusion.

For structural investigations of the imploded cryptophanes a $C_{1}$-symmetric out-saddle conformation of imploded cryptophane-A (impl-2) ${ }^{16}$, a $C_{3}$-symmetric in-out conformation of imploded cryptophane-E (impl-1) and a $C_{1}$-symmetric out-saddle conformation of impl-1 were optimized using M05-2X/6$31 G^{*}, c c-p V T Z$ (see Fig. 6). Based on these geometries single point calculations with B3LYP and B3LYP-D3 were carried out (Table 3 ). The calculations show that the $C_{1}$-symmetric outsaddle conformation of impl-1 is energetically more favourable than the $C_{3}$-symmetric in-out conformation (Table 3 ). Without taking the dispersion correction into account (by using the simple B3LYP method) the $D_{3}$-symmetric out-out conformers are much more stable than the corresponding imploded structures. This means that the intramolecular dispersion interactions between the CTV units is predicted to stabilize the imploded structures in contrast to the out-out cavity systems.

\section{Discussion}

We have shown that-in contrast to the scientific consensuscryptophanes are able to enclose bigger solvent molecules. Because of this inclusion the complex formation constants for cryptophane-guest complexes measured previously have been underestimated. If a solvent like 1,2-dichlorobenzene is used, which is enclosed less effectively by the cryptophane-E cavity, the binding constant for $\mathrm{CHCl}_{3} @$ cryptophane- $\mathrm{E}$ is two orders of magnitude higher. The reason for these high binding constants is predicted by the DFT simulations to be strong dispersion interactions. Using the B3LYP method an energetic stabilisation cannot be found for any guest. Only if the dispersion correction D3 is added, energetic stabilisation can be found. These corrections reach values from 25 to $46 \mathrm{kcal} \mathrm{mol}^{-1}$. As the dispersion interactions increase with the number of interacting atoms, a comparison is only reasonable if the dispersion correction for each interacting atom is regarded. The highest values are found for the chloroform complexes $(7.8 \mathrm{kcal}$ for $\mathrm{CHCl}_{3} @ 1,8.3 \mathrm{kcal}$ for $\mathrm{CHCl}_{3} @ 2$ and $8.5 \mathrm{kcal}$ for $\left.\mathrm{CHCl}_{3} @ 3\right)$. It has to be considered though that only the interaction energy during the inclusion of the halogen compounds into the cavity is calculated. It is not possible to make any statement with respect to solvent interaction and entropic factors. The inclusion of larger molecules like 1,1,2,2-tetrachloroethane and 1,2-dichlorobenzene, which according to experiments are disfavoured compared with chloroform binding, presumably leads to a high loss of entropy as the motion of the enclosed molecules is restricted. The calculations also explain the fact that $\mathrm{CHCl}_{3} @ 3$ in $\mathrm{C}_{2} \mathrm{H}_{2} \mathrm{Cl}_{4}$

Table 3 | Calculated relative gas phase energies.

\begin{tabular}{|c|c|c|c|c|}
\hline Host & Conformation & $\Delta E(M 05-2 X)^{\star}$ & $\Delta E(B 3 L Y P) \dagger$ & $\Delta E$ (B3LYP-D3) \\
\hline$D_{3}-1$ & out-out & 0.0 & 0.0 & 0.0 \\
\hline impl-1 & in-out & +10.1 & +31.0 & +6.7 \\
\hline impl-1 & out-saddle & +1.5 & +24.3 & -1.4 \\
\hline$D_{3}-2$ & out-out & 0.0 & 0.0 & 0.0 \\
\hline impl-2 & out-saddle & -2.9 & +14.3 & -2.1 \\
\hline
\end{tabular}

Calculated relative gas phase energies $\Delta E$ of theconformers of cryptophane-E (1) and cryptophane-A (2). All values are given in $\mathrm{kcal}^{\mathrm{mol}}{ }^{-1}$

${ }^{\star} \mathrm{M} 05-2 \mathrm{X} / 6-31 \mathrm{G}^{\star}, \mathrm{cc}-\mathrm{pVTZ} / / \mathrm{M} 05-2 \mathrm{X} / 6-31 \mathrm{G}^{\star}, \mathrm{cc}-\mathrm{pVTZ}$

$\dagger \mathrm{B} 3 \mathrm{LYP} / 6-311++\mathrm{G}^{\star \star}$, aug-cc-pVTZ//M05-2X/6-31G*,cc-pVTZ.

$\ddagger B 3 L Y P-D 3 / 6-311++G^{\star \star}$, aug-cc-pVTZ//M05-2X/6-31G* ,cc-pVTZ. 
exhibits a complex formation constant which is two magnitudes higher than that of $\mathrm{CHCl}_{3} @ \mathbf{1}$ in $\mathrm{C}_{2} \mathrm{H}_{2} \mathrm{Cl}_{4}$ : while the inclusion of solvent can be excluded by energetic reasons for compound $\mathbf{3}$, cryptophane-E is able to enclose solvent molecules.

The occurrence of a $C_{1}$-symmetric out-saddle conformation of impl-1 at higher temperatures implies that the empty host compound $D_{3}-1$ is quite unstable: The empty cryptophane-E either turns into the stable impl-1 form or immediately encloses a guest leading to the complex solvent@cryptophane-E. DFT calculations predict that intramolecular dispersion interactions between the CTV units are responsible for the fact that cryptophanes with empty cavities are only reactive intermediates. If no guest is enclosed, the more stable form is the corresponding imploded cryptophane.

\section{Methods}

Computational study. All calculations were performed by using the programme package Gaussian 09 (ref. 37) and MOLPRO ${ }^{38}$. Geometry optimizations were performed using the DFT potential M05-2 $\mathrm{X}^{31}$. For the light elements $\mathrm{C}, \mathrm{H}$ and $\mathrm{O}$ the $6-31 \mathrm{G}^{*}$ basis set was used, whereas for the halogens $\mathrm{Cl}$ and $\mathrm{Br}$ the cc-pVTZ basis set was employed. Compounds $\mathbf{1}$ and $\mathrm{CHCl}_{3} @ \mathbf{1}$ were completely geometrically optimized within the $C_{3}$ point group. All other compounds were optimized without any symmetry restriction. For the cryptophane-A and its complexes the gauche, trans, trans conformation of the - $\mathrm{O}-\mathrm{CH}_{2}-\mathrm{CH}_{2}$ - $\mathrm{O}$-bridges was taken, because this one is also found in the solid state ${ }^{39}$. To determine the structure of impl-1 several $\mathrm{C}_{3}$-symmetric in-out conformations of imploded cryptophane-E (impl-1) and several $C_{1}$-symmetric out-saddle conformations of impl-1 were optimized using M05-2X/6-31G ${ }^{*}, \mathrm{cc}-\mathrm{pVTZ}$. The conformers only vary in the conformation of the three propane bridges. Only the most stable in-out and out-saddle conformer are given in Table 3.

Based on the geometries obtained by M05-2X/6-31G*,cc-pVTZ, single point calculations with B3LYP ${ }^{32-34}$ and B3LYP-D3 (refs 35,36) were carried out. For the light elements $\mathrm{C}, \mathrm{H}$ and $\mathrm{O}$ the $6-311++\mathrm{G}^{* *}$ basis set was used, whereas for the halogens $\mathrm{Cl}$ and $\mathrm{Br}$ the aug-cc-pVTZ basis set was employed. See Supplementary Table 1 and Supplementary Data 1.

Experimental section. Cryptophane-E was synthesized according to literature procedures ${ }^{40}$. To guarantee that no undesired small solvent molecules are enclosed by the cryptophane, a big charge of cryptophane-E was firstly recrystallized from acetone and secondly from chloroform. Subsequent NMR measurements showed that the obtained crystals feature a cryptophane-E/chloroform ratio of 1:2. This ratio was also found by X-ray structure analysis of the solid ${ }^{18} \cdot{ }^{1} \mathrm{H},{ }^{13} \mathrm{C}$ NMR and 2D NMR spectra were measured with Bruker Avance DRX 500 and HD 600 spectrometers.

Characterisation data of cryptophane-E (1): mp. $308.5^{\circ} \mathrm{C} ;{ }^{1} \mathrm{H}$ NMR $(600 \mathrm{MHz}$ $\left.\mathrm{CDCl}_{3}\right): \delta=6.69\left(\mathrm{~s}, 6 \mathrm{H}, \mathrm{H}_{\mathrm{ar}}\right), 6.61\left(\mathrm{~s}, 6 \mathrm{H}, \mathrm{H}_{\mathrm{ar}}\right), 4.66\left(\mathrm{~d},{ }^{2} J_{\mathrm{H}, \mathrm{H}}=13.7 \mathrm{~Hz}, 6 \mathrm{H}, \mathrm{CH}_{2}\right)$, $4.06\left(\mathrm{~m}, 6 \mathrm{H}, \mathrm{CH}_{2}\right), 3.88\left(\mathrm{~m}, 6 \mathrm{H}, \mathrm{CH}_{2}\right), 3.83\left(\mathrm{~s}, 18 \mathrm{H}, \mathrm{OCH}_{3}\right), 3.43\left(\mathrm{~d},{ }^{2} J_{\mathrm{HH}}=13.8 \mathrm{~Hz}\right.$, $\left.6 \mathrm{H}, \mathrm{CH}_{2}\right), 2.31\left(\mathrm{~m}, 6 \mathrm{H}, \mathrm{CH}_{2}\right)$ p.p.m.; ${ }^{13} \mathrm{C}$ NMR $\left(151 \mathrm{MHz}, \mathrm{CDCl}_{3}\right): \delta=147.10$ $\left(\mathrm{q}, \mathrm{C}_{\mathrm{ar}}\right), 131.01\left(\mathrm{q}, \mathrm{C}_{\mathrm{ar}}\right), 130.96\left(\mathrm{q}, \mathrm{C}_{\mathrm{ar}}\right), 112.27\left(\mathrm{t}, \mathrm{C}_{\mathrm{ar}}\right), 112.03\left(\mathrm{t}, \mathrm{C}_{\mathrm{ar}}\right), 63.60$ $\left(\mathrm{s}, \mathrm{CH}_{2}\right), 55.62\left(\mathrm{p}, \mathrm{OCH}_{3}\right), 36.10\left(\mathrm{~s}, \mathrm{CH}_{2}\right), 29.65$ (s, $\left.\mathrm{CH}_{2}\right)$ p.p.m.; IR (ATR): $\tilde{v}=2,990,2,861,1,608,1,511,1,470,1,444,1,399,1,343,1,257,1,215,1,193,1,139$, $1,084,1,054,1,020,981,941,873,851,750,667 \mathrm{~cm}^{-1}$; UV/Vis (dichloromethane): $\lambda_{\max }(\log \varepsilon)=290$ (3.66), 232 (4.11), $208(4.40) \mathrm{nm}$; high-resolution mass spectrometry (electrospray ionization-positive) $(\mathrm{m} / \mathrm{z}):[\mathrm{M}+\mathrm{Na}]^{+}$calculated for $\mathrm{C}_{57} \mathrm{H}_{60} \mathrm{NaO}_{12}$, 959.3983; found, 959.3971.

\section{References}

1. Atwood, J. L. \& Steed, J. W. (eds) Encyclopedia of Supramolecular Chemistry (Taylor \& Francis, 2004).

2. Steed, J. W. \& Atwood, J. L. Supramolecular Chemistry (Wiley J. \& Sons, 2000).

3. Schneider, H. J. Binding mechanisms in supramolecular complexes. Angew. Chem. Int. Ed. 48, 3924-3977 (2009).

4. Salonen, L. M., Ellermann, M. \& Diederich, F. Aromatic rings in chemical and biological recognition: energetics and structures. Angew. Chem. Int. Ed. 50, 4808-4842 (2011)

5. Lehn, J.-M. Supramolecular Chemistry: Concepts and Perspectives (VCH, 1995).

6. Vögtle, F. \& Alfter, F. Supramolecular Chemistry: An Introduction (Wiley J. \& Sons, 1993).

7. Cram, D. J. \& Cram, J. M. Container Molecules and Their Guests (The Royal Society of Chemistry, 1997).

8. Conn, M. M. \& Rebek, J. Self-assembling capsules. Chem. Rev. 97, 1647-1668 (1997).

9. Jasat, A. \& Sherman, J. C. Carceplexes and hemicarceplexes. Chem. Rev. 99, 931-968 (1999).
10. Gabard, J. \& Collet, A. Synthesis of a $\left(D_{3}\right)$-Bis(cyclotriveratrylenyl) Macrocage by Stereospecific Replication of a $\left(C_{3}\right)$-Subunit. J. Chem. Soc. Chem. Commun. 1137-1139 (1981).

11. Collet, A. Cyclotriveratrylenes and cryptophanes. Tetrahedron 43, 5725-5759 (1987).

12. Brotin, T. \& Dutasta, J.-P. Cryptophanes and their complexes-present and future. Chem. Rev. 109, 88-130 (2009).

13. Garel, L., Dutasta, J. P. \& Collet, A. Complexation of methane and chlorofluorocarbons by cryptophane-a in organic solution. Angew. Chem. Int. Ed. Engl. 32, 1169-1171 (1993).

14. Bartik, K., Luhmer, M., Dutasta, J.-P., Collet, A. \& Reisse, J. ${ }^{129}$ Xe and ${ }^{1} \mathrm{H}$ NMR study of the reversible trapping of xenon by cryptophane-a in organic solution. J. Am. Chem. Soc. 120, 784-791 (1998).

15. Hill, P. A., Wei, Q., Troxler, T. \& Dmochowski, I. J. Substituent effects on xenon binding affinity and solution behavior of water-soluble cryptophanes. J. Am. Chem. Soc. 131, 3069-3077 (2009).

16. Taratula, O., Hill, P. A., Khan, N. S., Carroll, P. J. \& Dmochowski, I. J. Crystallographic observation of 'induced fit' in a cryptophane host-guest model system. Nat. Commun. 1, 148 (2010).

17. Canceill, J., Lacombe, L. \& Collet, A. A new cryptophane forming unusually stable inclusion complexes with neutral guests in a lipophilic solvent. J. Am. Chem. Soc. 108, 4230-4232 (1986)

18. Canceill, J. et al. Structure and properties of the cryptophane-E/ $\mathrm{CHCl}_{3}$ complex, a stable van der Waals molecule. Angew. Chem. Int. Ed. Engl. 28, 1246-1248 (1989).

19. Haberhauer, G. \& Rominger, F. Syntheses and structures of imidazole analogues of Lissoclinum cyclopeptides. Eur. J. Org. Chem. 3209-3218 (2003).

20. Pintér, Á. \& Haberhauer, G. Thieme chemistry journal awardees-where are they now? macrocyclic peptide chemistry inspired by nature-from chiral artificial receptors toward molecular devices. Synlett. 3082-3098 (2009).

21. Pintér, Á., Haberhauer, G., Hyla-Kryspin, I. \& Grimme, S. Configurationally stable propeller-like triarylphosphine and triarylphosphine oxide. Chem. Commun. 3711-3713 (2007)

22. Haberhauer, G., Oeser, T. \& Rominger, F. A $C_{3}$-symmetric molecular scaffold for the construction of large receptors. Chem. Commun. 2044-2045 (2004).

23. Haberhauer, G., Oeser, T. \& Rominger, F. Molecular scaffold for the construction of three-armed and cage-like receptors. Chem. Eur. J. 11, 6718-6726 (2005).

24. Haberhauer, G., Pintér, Á., Oeser, T. \& Rominger, F. Synthesis and structural investigation of $c_{4}$-and $c_{2}$-symmetric molecular scaffolds based on imidazole peptides. Eur. J. Org. Chem. 1779-1792 (2007).

25. Haberhauer, G., Pintér, Á. \& Woitschetzki, S. A very stable complex of a modified marine cyclopeptide with chloroform. Nat. Commun. 4, 2945 (2013).

26. Lang, J., Dechter, J. J., Effemey, M. \& Kowalewski, J. Dynamics of an inclusion complex of chloroform and cryptophane-E: evidence for a strongly anisotropic van der Waals bond. J. Am. Chem. Soc. 123, 7852-7858 (2001).

27. Zimmermann, H., Tolstoy, P., Limbach, H.-H., Poupko, R. \& Luz, Z. The saddle form of cyclotriveratrylene. J. Phys. Chem. B 108, 18772-18778 (2004).

28. Mough, S. T., Goeltz, J. C. \& Holman, K. T. Isolation and structure of an 'imploded' cryptophane. Angew. Chem. Int. Ed. 43, 5631-5635 (2004).

29. Huber, G. et al. Water soluble cryptophanes showing unprecedented affinity for xenon: candidates as nmr-based biosensors. J. Am. Chem. Soc 128, 6239-6246 (2006).

30. Bothner-By, A. A., Stephens, R., Lee, J., Warren, C. D. \& Jeanloz, R. Structure determination of a tetrasaccharide: transient nuclear overhauser effects in the rotating frame. J. Am. Chem. Soc. 106, 811-813 (1984).

31. Zhao, Y., Schultz, N. E. \& Truhlar, D. G. Design of density functionals by combining the method of constraint satisfaction with parametrization for thermochemistry, thermochemical kinetics, and noncovalent interactions. J. Chem. Theory Comput. 2, 364-382 (2006).

32. Becke, A. D. Density-functional exchange-energy approximation with correct asymptotic behavior. Phys. Rev. A 38, 3098 (1988).

33. Lee, C., Yang, W. \& Parr, R. G. Development of the Colle-Salvetti correlation-energy formula into a functional of the electron density. Phys. Rev. B 37, 785 (1988).

34. Miehlich, B., Savin, A., Stoll, H. \& Preuss, H. Results obtained with the correlation energy density functionals of Becke and Lee, Yang and Parr. Chem. Phys. Lett. 157, 200-206 (1989).

35. Grimme, S., Antony, J., Ehrlich, S. \& Krieg, H. A consistent and accurate ab initio parametrization of density functional dispersion correction (DFT-D) for the 94 elements H-Pu. J. Chem. Phys. 132, 154104 (2010).

36. Grimme, S. Supramolecular binding thermodynamics by dispersion-corrected density functional theory. Chem. Eur. J. 18, 9955-9964 (2012).

37. Pople, J. A. et al. Gaussian 09, revision A.02 (Gaussian, Inc., 2009).

38. Werner, H.-J. et al. MOLPRO, version 2012.1, http://www.molpro.net./ (2012).

39. Cavagnat, D. et al. Raman microspectrometry as a new approach to the investigation of molecular recognition in solids: chloroform-cryptophane complexes. J. Phys. Chem. B 108, 5572-5581 (2004). 
40. Canceill, J. \& Collet, A. Two-step synthesis of $D_{3}$ and $C_{3 h}$ cryptophanes. J. Chem. Soc. Chem. Commun. 582-584 (1988).

\section{Acknowledgements}

This work was generously supported by the Deutsche Forschungsgemeinschaft (DFG) We specially thank Patrizia Chamier-Cieminski, Helma Kallweit and Dr Silvia Ernst.

\section{Author contributions}

G.H. wrote the manuscript and performed the calculations. G.H. and S.W. determined the association constants of the complexes. H.B. and S.W. measured and analysed the NMR spectra.

\section{Additional information}

Supplementary Information accompanies this paper at http://www.nature.com/ naturecommunications

Competing financial interests: The authors declare no competing financial interests.

Reprints and permission information is available online at http://npg.nature.com/ reprintsandpermissions/

How to cite this article: Haberhauer, G. et al. Strongly underestimated dispersion energy in cryptophanes and their complexes. Nat. Commun. 5:3542 doi: 10.1038/ncomms4542 (2014). 